\title{
Adhesion to Zirconium Dioxide Used for Dental Reconstructions: Surface Conditioning Concepts, Challenges, and Future Prospects
}

\author{
Mutlu Özcan $^{1}$ • Claudia Angela Maziero Volpato ${ }^{2}$
}

Published online: 30 September 2015

(C) Springer International Publishing AG 2015

\begin{abstract}
Yttrium-stabilized zirconium dioxide, a commonly used material in conjunction with CAD/CAM technologies in dentistry, is an oxide ceramic that does not comprise the silicon dioxide $\left(\mathrm{SiO}_{2}\right)$ phase in its microstructure. Since it is challenging to create durable adhesion between resin cements and this kind of non-etchable ceramic, efforts have been made to develop innovative surface conditioning methods over the years. While some chemical methods based on using adhesion promoters only did not perform stable adhesion, others utilizing physico-chemical conditioning methods provided better adhesion where the latter is also being questioned on impairing mechanical stability of zirconium dioxide $\left(\mathrm{ZrO}_{2}\right)$ due to $t \rightarrow m$ phase transformation. This review will highlight current surface conditioning concepts to achieve best adhesion to zirconium dioxide and challenges related to conditioning methods or resin-based luting cements, and contemplate on future prospects.
\end{abstract}

Keywords Adhesion - Resin-bonded fixed dental prosthesis · Resin cements · Surface conditioning · Y-TZP · Zirconium dioxide

This article is part of the Topical Collection on Dental Restorative Materials

Mutlu Özcan

mutluozcan@hotmail.com

1 Dental Materials Unit, Center for Dental and Oral Medicine, Clinic for Fixed and Removable Prosthodontics and Dental Materials Science, University of Zurich, Plattenstrasse 11, CH-8032 Zurich, Switzerland

2 Health Sciences Center, Department of Dentistry, Federal University of Santa Catarina, Florianópolis, Brazil

\section{Introduction}

With advances in adhesive dentistry over the last few decades, and especially after the introduction of CAD/CAM technology, many clinical cases restored with metal-ceramic fixed dental prostheses (FDP) are currently being solved with metalfree materials, one of which is yttrium-stabilized tetragonal zirconia polycrystal (hereon zirconia).

\section{Zirconia as a Material}

Among numerous other ceramic options, zirconia drew considerable attention of the scientists and clinicians in the dental field due to its favorable mechanical properties $[1,2]$. This biocompatible, chemically bioinert ceramic has potential for versatile applications in dentistry other than FDPs such as root posts, orthodontics brackets, implants, or implant abutments.

The microstructure of zirconia consists of about 2.5 to $3.5 \%$ yttrium oxide $\left(\mathrm{Y}_{2} \mathrm{O}_{3}\right)$ and is formed mostly by particles of micrometric $\mathrm{ZrO}_{2}$ after sintering from a metastable tetragonal structure at room temperature [3, 4]. Zirconia has a standard density of $6 \mathrm{~g} / \mathrm{cm}^{3}$, while its theoretical density is $6.51 \mathrm{~g} /$ $\mathrm{cm}^{3}$. The closer these two values are, the smaller the interparticle space and, thereby, the greater the strength and the smoother the surface of the material [5].

\section{Zirconia and Transformation Change}

As a function of temperature alteration, pure zirconia exhibits three polymorphic phases, also known as allotropic or crystalline phases. While at temperatures up to $1170{ }^{\circ} \mathrm{C}$ the material presents a monoclinic phase, tetragonal structure can be observed at intermediate temperatures $\left(1170-2370{ }^{\circ} \mathrm{C}\right)$ and 
finally the material exhibits a stable cubic structure at high temperatures $\left(>2370^{\circ} \mathrm{C}\right)[3,6]$. Among all these three phases, the monoclinic phase has inferior mechanical properties, which actually helps reduce the cohesion between particles but at the same time diminish the final density of the material. In order to be able to use zirconia as a framework material for FDPs, it is essential to have stabilized tetragonal or cubic phases at room temperature. For better control of the phase transformation, oxides $(\mathrm{CaO}, \mathrm{MgO})$ and rare earths $\left(\mathrm{CeO}_{2}\right.$, $\mathrm{Y}_{2} \mathrm{O}_{3}$ ) are used as stabilizers preventing phase transformations that may occur during veneering procedures [7].

According to the ISO assigned for biomedical applications, $\mathrm{Y}_{2} \mathrm{O}_{3}$ is extracted from a xenotime mineral and it is the most commonly used stabilizer for such applications [8]. Unfortunately, when subjected to pressure or any kind of impact, the stabilized zirconia can undergo tetragonal metastable to monoclinic $(t \rightarrow m)$ transformation $[1,3,4]$. This type of transformation is accompanied by a volume increase of 3 to $5 \%$ that tends to induce compressive stress in the transformed region that in turn prevents crack propagation [3]. Toughening by transformation is strongly dictated by the presence of defects on material, size of $\mathrm{ZrO}_{2}$ grains, type and amount of stabilizers, and radiant of temperature [9•]. Small grains are essentially more prone to transformation than larger grains, but there is a critical grain size, below $\approx 0.2 \mu \mathrm{m}$, where the transformation does not occur. However, above that grain size, transformation occurs spontaneously [10]. Moreover, while some grains undergo transformation at room temperature, others require an increased temperature for this process mainly due to their smaller size $[10,11]$.

\section{Surface Conditioning Methods for Zirconia}

Hydrofluoric acid (HF) etching followed by the application of silane coupling agents is a well-established conditioning method and delivers durable adhesion to glassy matrix ceramics used for dental applications. Unfortunately, this method does not provide adequate adhesion to zirconia since it does not contain a silica phase. Achieving durable resin cement adhesion to zirconia becomes particularly crucial to increase the clinical indication of surface-retained resin-bonded FDPS where the retention solely relies on durable adhesion of the tooth-resin-zirconia complex. While some surface conditioning methods facilitate resin-ceramic bonding micromechanically using airborne particle abrasion with alumina particles or alumina, other methods are based on physico-chemical activation of the surface using silicacoated alumina particles or silica particles alone followed by silanization $[9 \bullet, 12 \bullet \bullet]$.

Alternative surface modification methods such as selective infiltration etching (SIE) [13, 14], glaze ceramic coating [15], chemical plasma vapor deposition using hexamethyldisiloxane or chlorosilane gas [16], erbium-doped yttrium aluminum garnet (Er:YAG) laser application [15, 17], and physical vapor deposition using a magnetron sputtering technique (RMS) [18, 19] have also been tried in an attempt to improve adhesion to zirconia. In the SIE method, low temperature fused glass ceramic is applied to the selected surface that is then etched with $5 \% \mathrm{HF}$ solution. Etching process establishes porosities between the grains that are then filled with low-viscosity resin cement [14]. Despite the fact that this method provides initially favorable adhesion, hydrolytic stability after aging tends to reduce the achieved results [13]. On the other hand, the plasma spraying method, using hexamethyldisiloxane, is a rapid process that can be accomplished at low temperatures. In this method, a reactor generates an ionized gas deposited on the zirconia surface where the chemical configuration and film thickness can be controlled during application. Nevertheless, the adhesion mechanism is not yet clear and, in fact, the working mechanism is postulated to work with covalent bonds between adhesive luting cement and zirconia rather than the chemical reaction achieved by the plasma coating [16]. Similarly, the RMS method is based on deposition of high-energy particles on solid surfaces creating free radicals. The released particles scatter through the plasma of the inert gas at low pressure, depositing a uniform and controlled film and activating the substrate for improved adhesion without compromising the mechanical properties of the substrate [18, 19].

One other method known as Er:YAG laser ablation uses laser irradiation that creates a rough zirconia surface [17, 20]. Yet, studies have shown that laser irradiation is not as effective as airborne particle abrasion methods in improving adhesion of resin cements to zirconia [21]. Other coating methods using micropearls of low-fusing ceramic or vapor deposition of silicon tetrachloride $\left(\mathrm{SiCl}_{4}\right)$ have shown worthy results of adhesion [22], but again, glass deposition was found critical to interfere with the internal adaptation of the reconstruction [23, 24].

Achieving a clean substrate surface is essential for durable adhesion to all materials. In that respect, air abrasion eliminates organic contaminants such as cement, plaster, and saliva debris from the ceramic surface after the clinical and laboratory steps [25••, 26•, 27] that increases the wetting kinetics of adhesives [28-31]. Moreover, due to surface roughness, an increase in surface area of approximately $80 \%$ can be attained that expands bonding sites available to react with an adhesive promoter [3]. In dentistry, air-abrasion systems are practiced using different particle types and sizes ranging from 30 to $250 \mu \mathrm{m}$ [3, 12••] where particles of $110-250 \mu \mathrm{m}$ are typically used in dental laboratories and 30-50 $\mu \mathrm{m}$ particles at chairside [3, 12••, 19, 32-35].

The most commonly used particle types are alumina $\left(\mathrm{Al}_{2} \mathrm{O}_{3}\right)$ or alumina-coated silica $\left(\mathrm{SiO}_{2}\right)$. When alumina particles are coated with silica through the sol-gel method, a silica layer is deposited on the zirconia, which allows interaction with the subsequently applied silane coupling agents, forming hydrolytically more stable $-\mathrm{Si}-\mathrm{O}-\mathrm{Si}-\mathrm{O}-$ bonds compared to 
-Al-O-Si- [36]. The silane coupling agent with its bifunctional characteristics is capable of reacting with silicon dioxide $\left(\mathrm{SiO}_{2}\right)$ deposited on the zirconia surface, and copolymerizes with the organic matrix of the resin luting cement $[10,36]$. This technique known as tribochemical silica coating [32] demonstrated better adhesion results between resin luting cements and zirconia as opposed to conditioning the surface with conventional $\mathrm{Al}_{2} \mathrm{O}_{3}$ particles $[12 \bullet \bullet, 16,25 \bullet \bullet, 33]$. It has to be emphasized that the effectiveness of air-abrasion methods depends highly on the deposition parameters such as type and size of the particles, pressure, angle and distance of the nozzle in relation to the substrate surface, and duration [37]. Different particle sizes ranging from 25 to $250 \mu \mathrm{m}$, pressure from 0.5 to $7 \mathrm{bar}$, and duration of 5 to $20 \mathrm{~s}$ were employed in previous studies which make it difficult to make direct comparisons of the results [12••]. Fortunately, recent metaanalysis of the published data verified the efficacy of airabrasion concepts for improved adhesion to zirconia [12••, $25 \cdot \bullet]$.

\section{Concerns on Air Abrasion}

To date, controversial opinions are present regarding the harmful effects of particle deposition methods on zirconia [38, 39, 40••, $41,42]$, in that momentum of particles on zirconia yields to local lattice distortions or creates a new phase by ferroelastic domain switching. In fact, the impact of particle deposition methods on zirconia is dependent on parameters such as particle morphology, pressure, and duration [37] effecting a residual compressive stress layer that stimulates phase transformation $(t \rightarrow m)$ and creates transformed zone depth (TZD) $[9 \bullet, 40 \bullet$. TZD typically ranges from 0.59 to $1.6 \mu \mathrm{m}$, and interestingly, with the good combination of deposition parameters, this zone may even increase the mechanical strength of zirconia $[38,40 \bullet, 41,42]$. ISO standard 13356 suggests $25 \%$ as the maximum acceptable amount of monoclinic phase [8]. In fact, the highest amount reported so far even in the harshest conditions barely exceeded this limit. Thus, delicate application of air-abrasion protocols, using a smaller particle size of $50 \mu \mathrm{m}$ or less, as short as possible (approximately $20 \mathrm{~s} / \mathrm{cm}^{2}$ ) between 0.5 and 2.5 bar and with controlled nozzle distance of approximately $10 \mathrm{~mm}$, is among currently accepted conditioning parameters $[9 \bullet, 35,37]$. The increase in pressure during air-abrasion procedures can produce even deeper surface morphology, hindering the wettability and flow of resin luting cement into the irregularities [39, 42].

\section{Resin Luting Cements}

The choice of resin cements also plays a significant role in adhesion to zirconia. Phosphate ester monomer-containing adhesion promoters with polar functional groups such as 10- methacryloyloxydecyl dihydrogenphosphate (10-MDP) $[12 \bullet \cdot, 43,44]$ could make covalent bonds with the hydroxyl groups on the zirconia surface. Currently, alumina or silica coating followed by the application of MDP-containing silane coupling agent and MDP-based resin cement appears to be more resistant to aging $[12 \bullet \bullet, 45]$ compared to methacrylatebased conventional resin luting cements [12••, 25••, 33, 46].

While concerns exist about the potential damage by airabrasion protocols on zirconia, some manufacturers started to promote chemical activation of the surface with selfadhesive cements. When conventional resin cements are used, conditioning zirconia surface is mandatory. In contrast, selfadhesive resin cements do not require physical and/or chemical conditioning of neither zirconia nor dental tissues, saving clinical time, which also do not compromise the strength of zirconia. This type of self-adhesive cements show great variation in their chemical compositions in that while some contain phosphoric acid esters, MDP, bis-HEMA-phosphate, glycerolphosphate dimethacrylate, and 4-META, others contain bis-GMA alone or in combination with TEG-DMA. Unfortunately, low degree of conversion of such acidic monomers, less hydrolytic stability, and low diffusion level into dentin are limitations of self-adhesive cements [47, 48].

\section{On Aging of Adhesive Interfaces and Zirconia Itself}

In adhesion studies, the bonded joints are subjected to different aging conditions to estimate the long-term clinical behavior $[49 \bullet \bullet, 50]$. While water storage mimics aging due to water uptake and hydrolytic degradation, thermocycling characterizes hydrothermal aging where the latter significantly reduces adhesion [51]. Aging conditions show big variation, making comparisons between studies difficult. Some standardization on the aging protocol seems to be crucial but generally contingent on the specimen dimensions for each in vitro test method; water storage may result in hydrolysis of the adhesive joint similar to thermocycling. In a systematic review of parameters in dentin bonding studies, both thermocycling and long-term water storage did not show high sensitivity but water storage presented a greater bond-degrading effect [52]. Future studies on adhesion tests should consider the degrading effect of water storage versus thermocycling.

Similar to adhesion-related studies, fatigue studies on zirconia also present huge scatter of fatigue parameters in aging this material. In the dental literature, cycling loading of minimum 10,000 cycles at $1 \mathrm{~Hz}$ between 30 and $300 \mathrm{~N}$ and maximum $1,200,000$ cycles at $50 \mathrm{~N}$ at $1.3 \mathrm{~Hz}$ are practiced [3]. The use of dynamic and cyclic tests after air abrasion with $50 \mu \mathrm{m}$ alumina or alumina particles coated with silica resulted in significant reduction in surface flaws and could even improve fatigue resistance of zirconia [53]. 


\section{Concluding Remarks}

Retention loss of zirconia-based crowns or FDPs is a rare event according to the clinical studies [54, 55, 56••, 57, 58]. Only in the case of minimally invasive resin-bonded FDPs made of zirconia is durable adhesion essential. Since many confounding factors are present in clinical trials, in vitro studies will remain to serve for ranking materials and identify the best performing ones in worst-case scenarios prior to such trials. At the moment, MDP-based adhesive promoters and resin cements seem to deliver reliable adhesion to zirconia. In addition, air abrasion increases micromechanical retention, but moderately rough surface that does not yield to monoclinic phase formation requires meticulous air-abrasion procedures. Clinicians should also note that durable adhesion of zirconia FDPs to enamel and dentin requires adequate surface conditioning of the two substrates, which may be based on several steps, and the choice of resin cement that adheres to both substrates [59]. Future developments in surface conditioning methods aim for reducing or completely eliminating these multistep procedures and achieving a surface on zirconia that delivers adhesion similar to glassy matrix ceramics or polymeric materials. This will mean either further development of resin cements that do not suffer from aging or new conditioning methods that have more potential for chairside applications.

\section{Compliance with Ethics Guidelines}

Conflict of Interest The authors declare that they have no conflict of interest.

Human and Animal Rights and Informed Consent This article does not contain any studies with human or animal subjects performed by any of the authors.

\section{References}

Papers of particular interest, published recently, have been highlighted as:

- Of importance

•- Of major importance

1. Miyazaki T, Nakamura T, Matsumura $\mathrm{H}$, et al. Current status of zirconia restoration. J Prosthodont Res. 2013;57(4):236-61.

2. Ferrari M, Vichi A, Zarone F. Zirconia abutments and restorations: from laboratory to clinical investigations. Dent Mater. 2015;31(3): e63-76.

3. Denry I, Kelly JR. State of the art of zirconia for dental applications. Dent Mater. 2008;24(3):299-307.

4. Vagkopoulou T, Koutayas SO, Koidis P, et al. Zirconia in dentistry: part 1. Discovering the nature of an upcoming bioceramic. Eur J Esthet Dent. 2009;4(2):130-51.
5. Duran P, Moure C. Sintering at near theoretical density and properties of PZT ceramics chemically prepared. J Mater Sci. 1984;20(3): 827-33.

6. Kisi EH, Howard CJ. Crystal structures of zirconia phases and their inter-relation. Key Eng Mater. 1998;153:1-36.

7. Hannink RHJ, Kelly PM, Muddle BC. Transformation toughening in zirconia-containing ceramics. J Am Ceram Soc. 2000;83(3):46187.

8. International Standards Organization: implants for surgery-ceramic materials based on yttria-stabilized tetragonal zirconia (YTZP). 2008

9. Özcan M. Airborne particle abrasion of zirconia fixed dental prostheses. J Esthet Restor Dent. 2014;26(6):359-62. This review article focuses on the effect of air-abrasion parameters on durability of zirconia and suggests the safest deposition parameters.

10. Zhu WZ. Grain size dependence of the transformation temperature of tetragonal to monoclinic phase in $\mathrm{ZrO}_{2}\left(\mathrm{Y}_{2} \mathrm{O}_{3}\right)$ ceramics. Ceram Int. 1996;22:389-95.

11. Schmauder S, Schubert U. Significance of internal stresses for the martensitic transformation in yttria-stabilized tetragonal zirconia polycrystals during degradation. J Am Ceram Soc. 1986;69:534 40.

12.• Özcan M, Bernasconi M. Adhesion to zirconia used for dental restorations: a systematic review and meta-analysis. J Adhes Dent. 2015;17(1):7-26. This is one of the three meta-analyses currently available on adhesion to zirconia. The paper concludes that adhesion to zirconia can be improved by employing physicochemical surface conditioning methods followed by the use of MDP-based resin cement.

13. Aboushelib MN, Mirmohamadi H, Matinlinna JP, et al. Innovations in bonding to zirconia-based materials. Part II: focusing on chemical interactions. Dent Mater. 2009;25(8):989-93.

14. Aboushelib MN. Evaluation of zirconia/resin bond strength and interface quality using a new technique. J Adhes Dent. 2011;13(3):255-60.

15. Cavalcanti AN, Foxton RM, Watson TF, et al. Bond strength of resin cements to a zirconia ceramic with different surface treatments. Oper Dent. 2009;34(3):280-7.

16. Derand T, Molin M, Kvam K. Bond strength of composite luting cement to zirconia ceramic surfaces. Dent Mater. 2005;21(12): $1158-62$.

17. Gomes AL, Ramos JC, Santos-del Riego S, et al. Thermocycling effect on microshear bond strength to zirconia ceramic using Er: YAG and tribochemical silica coating as surface conditioning. Lasers Med Sci. 2015;30(2):787-95.

18. Queiroz JRC, Duarte DA, Souza ROA, et al. Deposition of $\mathrm{SiO}_{\mathrm{x}}$ thin films on Y-TZP by reactive magnetron sputtering: influence of plasma parameters on the adhesion properties between Y-TZP and resin cement for application in dental prosthesis. Mater Res. 2011;14(2):212-6.

19. Queiroz JRC, Massi M, Nogueira Jr L, et al. Silica-based-nanocoating on zirconia surfaces using reactive magnetron sputtering: effect on chemical adhesion of resin cements. J Adhes Dent. 2013;15(2):151-9.

20. Kasraei S, Rezaei-Soufi L, Heidari B, et al. Bond strength of resin cement to $\mathrm{CO}_{2}$ and Er:YAG laser-treated zirconia ceramics. Restor Dent Endod. 2014;39(4):296-302.

21. Cattani Lorente M, Scherrer SS, Richard J, et al. Surface roughness and EDS characterization of a Y-TZP dental ceramic treated with the CoJet ${ }^{\mathrm{TM}}$ Sand. Dent Mater. 2010;26(11):1035-42.

22. Ntala P, Chen X, Niggli J, et al. Development and testing of multiphase glazes for adhesive bonding to zirconia substrates. J Dent. 2010;38(10):773-81.

23. Cura C, Özcan M, Isik G, et al. Comparison of alternative adhesive cementation concepts for zirconia ceramic: glaze layer vs zirconia primer. J Adhes Dent. 2012;14(1):75-82. 
24. Castro HL, Corazza PH, Paes-Júnior Tde A et al. Influence of YTZP ceramic treatment and different resin cements on bond strength to dentin. 2012;28(11):1191-7.

25.• Inokoshi M, De Munck J, Minakuchi S, et al. Meta-analysis of bonding effectiveness to zirconia ceramics. J Dent Res. 2014;93(4):329-34. This systematic review concludes similar to reference number 12.

26. Özcan M. Air abrasion of zirconia resin-bonded fixed dental prostheses prior to adhesive cementation: why and how? J Adhes Dent. 2013;15(4):394. In this paper, working instructions are provided for the clinicians on how to condition zirconia in a step-by-step manner. The instructions are based on the best available evidence from in vitro studies, justifying the reason for each procedure.

27. Ishii R, Tsujimoto A, Takamizawa $\mathrm{T}$, et al. Influence of surface treatment of contaminated zirconia on surface free energy and resin cement bonding. Dent Mater J. 2015;34(1):91-7.

28. Blatz MB, Chiche G, Holst $\mathrm{S}$, et al. Influence of surface treatment and simulated aging on bond strengths of luting agents to zirconia. Quintessence Int. 2007;38(9):745-53.

29. Piascik JR, Grego S, Stoner BR, et al. Surface modification for enhanced silanation of zirconia ceramics. Dent Mater. 2009;25(9): 1116-21.

30. Attia A. Bond strength of three luting agents to zirconia ceramic influence of surface treatment and thermocycling. J Appl Oral Sci. 2011;19(4):388-95.

31. Thompson JY, Stoner BR, Piascik JR, et al. Adhesion/cementation to zirconia and other non-silicate ceramics: where are we now? Dent Mater. 2011;27(1):71-82.

32. Guggenberger R. Rocatec system-adhesion by tribochemical coating. Dtsch Zahnartl Z. 1989;44(11):874-6.

33. Kern M, Wegner SM. Bonding to zirconia ceramic: adhesion methods and their durability. Dent Mater. 1998;14(1):64-71.

34. Atsu SS, Kilicarslan MA, Kucukesmen HC, et al. Effect of zirconium-oxide ceramic surface treatments on the bond strength to adhesive resin. J Prosthet Dent. 2006;95(6):430-6.

35. Baldissara $\mathrm{P}$, Querzè $\mathrm{M}$, Monaco $\mathrm{C}$, et al. Efficacy of surface treatments on the bond strength of resin cements to two brands of zirconia ceramic. J Adhes Dent. 2013;15(3):259-67.

36. Özcan M, Vallittu PK. Effect of surface conditioning methods on the bond strength of luting cement to ceramics. Dent Mater. 2003;19(8):725-31.

37. Kosmac T, Oblak C, Jevnikar P, et al. Strength and reliability of surface treated Y-TZP dental ceramics. J Biomed Mater Res. 2000;53(4):304-13.

38. Özcan M, Raadschelders J, Vallittu P, et al. Effect of particle deposition parameters on silica coating of zirconia using a chairside airabrasion device. J Adhes Dent. 2013;15(3):211-4.

39. Zhang Y, Lawn BR, Rekow ED, et al. Effect of sandblasting on the long-term performance of dental ceramics. J Biomed Mater Res B Appl Biomater. 2004;71(2):381-6.

40.• Özcan M, Melo RM, Souza RO, et al. Effect of air-particle abrasion protocols on the biaxial flexural strength, surface characteristics and phase transformation of zirconia after cyclic loading. J Mech Behav Biomed Mater. 2013;20:19-28. This article presents the amount of monoclinic phase as a function of particle size and morphology, and duration of deposition. Suggestions are made for the best air-abrasion protocol in order not to impair the mechanical properties of zirconia.

41. Turp V, Sen D, Tuncelli B, et al. Evaluation of air-particle abrasion of Y-TZP with different particles using microstructural analysis. Aust Dent J. 2013;58(2):183-91.

42. Sarmento HR, Campos F, Sousa RS, et al. Influence of air-particle deposition protocols on the topography and adhesion of resin cement to zirconia. Acta Odontol Scand. 2014;72(5):346-53.
43. Oyagüe RC, Monticelli F, Toledano M, et al. Influence of surface treatments and resin cement selection on bonding to denselysintered zirconium-oxide ceramic. Dent Mater. 2009;25(2):172-9.

44. Behr M, Proff P, Kolbeck C, et al. The bond strength of the resin-tozirconia interface using different bonding concepts. J Mech Behav Biomed Mater. 2011;4(1):2-8.

45. Inokoshi M, Poitevin A, De Munck J, et al. Bonding effectiveness to different chemically pre-treated dental zirconia. Clin Oral Investig. 2014;18(7):1803-12.

46. May LG, Passos SP, Capelli DB, et al. Effect of silica coating combined to a MDP-based primer on the resin bond to Y-TZP ceramic. J Biomed Mater Res B Appl Biomater. 2010;95(1):69-74.

47. Monticelli F, Osorio R, Mazzitelli C, et al. Limited decalcification/ diffusion of self-adhesive cements into dentin. J Dent Res. 2008;87: 974-9.

48. Vrochari AD, Eliades G, Hellwig E, et al. Curing efficiency of four self-etching, self-adhesive resin cements. Dent Mater. 2009;25(9): 1104-8.

49.• Morresi AL, D'Amario M, Capogreco M, et al. Thermal cycling for restorative materials: does a standardized protocols exist in laboratory testing? A literature review. J Mech Behav Biomed Mater. 2014:29:295-308. This literature review critically analyzes the aging parameters employed in the dental literature. Authors concluded that a standard thermocycling procedure does not exist.

50. Karimipour-Saryazdi M, Sadid-Zadeh R, Givan D, et al. Influence of surface treatment of yttrium-stabilized tetragonal zirconium oxides and cements type on crown retention after artificial aging. J Prosthet Dent. 2014;111(5):395-403.

51. Blatz MB, Sadan A, Martin J, et al. In vitro evaluation of shear bond strengths of resin to densely-sintered high-purity zirconium-oxide ceramic after long-term storage and thermal cycling. J Prosthet Dent. 2004;91(4):356-62.

52. De Munck J, Mine A, Poitevin A, et al. Meta-analytical review of parameters involved in dentin bonding. J Dent Res. 2012;91(4): 351-7.

53. Scherrer SS, Cattani-Lorente M, Vittecoq E, et al. Fatigue behavior in water of Y-TZP zirconia ceramics after abrasion with $30 \mu \mathrm{m}$ silica-coated alumina particles. Dent Mater. 2011;27(2):e28-42.

54. Ortorp A, Kihl ML, Carlsson GE. A 5-year retrospective study of survival of zirconia single crowns fitted in a private clinical setting. J Dent. 2012;40(6):527-30.

55. Raigrodski AJ, Hillstead MB, Meng GK, et al. Survival and complications of zirconia-based fixed dental prostheses: a systematic review. J Prosthet Dent. 2012;107(3):170-7.

$56 . \bullet$ Larsson C, Wennerberg A. The clinical success of zirconia-based crowns: a systematic review. Int J Prosthodont. 2014;27(1):33-43. According to this review, 5-year survival rates of zirconia crowns are $95.9 \%$ for tooth-supported and $97.1 \%$ for implant-supported ones. While for implant-supported crowns, the most common reasons for failure were veneering ceramic fractures, for tooth-supported crowns, veneering material fractures, loss of retention, and endodontic/periodontic complications were common.

57. Salido MP, Martinez-Rus F, del Rio F, et al. Prospective clinical study of zirconia-based posterior four-unit fixed dental prostheses: four-year follow-up. Int J Prosthodont. 2012;25(4):403-9.

58. Näpänkagas R, Pihlaja J, Raustia A. Outcome of zirconia single crowns made by predoctoral dental students: A clinical retrospective study after 2 to 6 years of clinical service. J Prosthet Dent. 2015;113(4):289-94.

59. Saker S, Ibrahim F, Özcan M. Effect of different surface treatments on adhesion of In-Ceram Zirconia to enamel and dentin substrates. J Adhes Dent. 2013;15(4):369-76. 